\title{
Seasonal Changes in Performance Related Characteristics and Biochemical Marker Variability of Adolescent Table Tennis Players
}

\author{
Samuel Andrew Pullinger (iD ${ }^{1,}{ }^{*}$, Evdokia Varamenti ${ }^{1}$, Zoran Nikolovski ${ }^{1}$, Mohamed Elgingo ${ }^{1}$ and \\ Marco Cardinale (iD) ${ }^{1,2}$ \\ ${ }^{1}$ Aspire Academy for Sports Excellence, Doha, Qatar \\ ${ }^{2}$ Department of Computer Science, Institute of Sport Exercise and Health, University College London, London, United Kingdom \\ "Corresponding author: Aspire Academy for Sports Excellence, P.O. Box. 22287, Doha, Qatar. Email: samuel.pullinger@aspire.qa
}

Received 2018 February 09; Revised 2019 January 02; Accepted 2019 February 16.

\begin{abstract}
Background: There is a shortage of longitudinal surveys in highly trained adolescent table tennis athletes reporting typical changes in performance related, hematological, and biochemical parameters.

objectives: The purpose of the study was to: (1) examine yearly variations of performance related parameters, and (2) report the variability of selected hematological and biochemical markers utilized to ascertain health status, and training influences in a group of young Arab table tennis athletes.

Methods: Data were collected from ten male adolescent players with a mean age of $14.2 \pm 1.3$ years and a mean table tennis training experience of 6 years. Physical and biochemical measures were carried out at three important time points throughout the training season: a baseline measure (PRE - September); a mid-season (transition) measure (MID - February); an end of season measure (END May).

Results: Performance related parameters tended to significantly improve over time $(P=0.05)$, with lowest values displayed during PRE-measure. Hematocrit $(P=0.05)$, serum testosterone $(P=0.01)$, mean cell volume $(M C V)(P=0.001)$ and reticulocytes $(R E T)(P$ $=0.017)$ significantly increased at the END training period compared to PRE. Moreover, $25(\mathrm{OH}) \mathrm{D}$ levels $(\mathrm{P}=0.001)$ showed a drop during MID to then significantly increase at the END whilst sex hormone binding globulin (SHBG; $\mathrm{P}=0.005)$ decreased at the END period compared to MID.

Conclusions: In conclusion, based on our findings, changes in certain physical parameters and, hematological and biochemical markers, take place during the training period. Therefore, coaches, sports scientists and nutritionists should take into consideration these fluctuations and plan and alter their training programs accordingly.
\end{abstract}

Keywords: Racquet Sport, Hematology, Exercise Physiology, Adolescent Boys, Exercise Testing

\section{Background}

Table tennis is a complex racket sport that is characterized by an intermittent activity profile. It involves complex skills, physiological and cognitive demands with success highly dependent on the interaction of all these performance factors $(1,2)$. The requirement of physical abilities is significant. A well-developed aerobic and anaerobic energy system is vital to excel as an elite table tennis player (3-5). Furthermore, a high level of physical fitness aids recovery, reduces injury risk and helps players with decision-making abilities to guarantee a higher level of performance during training and competition (5). To reach top-level performances in table tennis, several years of specific training combined with challenging strength and conditioning activities are required to ensure physi- cal adaptations take place. These can further enhance the given metabolic pathways for energetic supply to the skeletal muscles (6).

The pubertal growth spurt, as observed during early adolescence, is influenced by the release of important hormones that have shown to influence the development of physical capacity and performance during childhood to adolescence. It has been suggested that monitoring testosterone levels can provide information about maturation and growth. Cortisol and testosterone represent the anabolic-catabolic equilibrium of an athlete and could provide information regarding overtraining or insufficient recovery (7). The changes in levels in serum testosterone (an anabolic indicator that stimulates muscle protein synthesis), and serum cortisol (an indicator of catabolic state which plays a significant role in gluconeo- 
genesis) can provide in-depth information regarding long term training adaptations and stress/overtraining (8).

Additional biochemical markers have been suggested to be linked to growth. In fact, current work on 25 hydroxyvitamin $\mathrm{D}(25(\mathrm{OH}) \mathrm{D})$ has highlighted its influence in muscle growth and differentiation and has been closely associated with muscle injuries (9). Considering the prevalence of hypovitaminosis D in Arab adolescents $(10,11)$ and the nature of table tennis training activities being limited to indoor facilities, it is expected that table tennis athletes might represent an "at risk" population. Therefore, regular assessment of $25(\mathrm{OH}) \mathrm{D}$ is required to ensure they can compensate for lack of sun exposure. In addition, regular screening of iron status and complete blood count parameters can provide useful information about the potential for performance. It has been found that athletes with a sub-optimal iron status may experience reduced exercise capacity and compromised sports performance (12).

Despite the growing interest and number of players engaged worldwide in table tennis, there is a paucity of studies providing accurate training information on adolescent players. Many adolescent athletes follow regular and structured training activities often comparable to adult counterparts (3). Such activities can either have positive or negative consequences on growth, metabolites, enzymes and hematological parameters. The training load imposed and its progression as well as competition stresses play a significant role in inducing hormonal and/or inflammatory effects. No information is available regarding the hematological, hormonal and enzymatic activity variability during an annual training cycle in young table tennis athletes. Therefore, through the screening of young athletes at specific time-points of the year, in-depth information can be collected to help safeguard the athlete's health and, potentially, determine the implications of the applied training loads on growth and maturation in youth table tennis athletes.

\section{Objectives}

Therefore, the purpose of the study was to examine: (1) the yearly fluctuations of performance related parameters and (2) report the variability of several selected biomarkers utilized to ascertain health status, and training influences throughout a yearly training season in a group of young Arab table tennis athletes.

\subsection{Hypothesis}

We hypothesized that as the training load and intensity of training increases over a season, physical performance of athletes will also display an increase. In addition, because of pubertal growth and increases in training load and intensity of training, there will be fluctuations in numerous hematological and biochemical markers at different time-points of the training season.

\section{Methods}

\subsection{Selection and Description of Participants}

Ten male adolescent table tennis athletes of Arabic origin (age (mean \pm SD) $14.2 \pm 1.3$ years, body mass $56.0 \pm$ $15.2 \mathrm{~kg}$, stature $164.9 \pm 10.5 \mathrm{~cm}$, BMI $20.3 \pm 4.0$ and PHV $0.27 \pm 1.40$ at the start of collection) were included in this prospective study. All participants were required to be members and players currently representing the Qatar Table Tennis Association and current students at Aspire Academy for Sporting Excellence. Any individuals who did not meet these criteria were discarded from the study. At the time of first screening all athletes were given clearance from a physician to train and were not taking any medication. Written informed consent was sought and obtained from all participants and their parents. The procedures employed in the study were reviewed and approved by the Aspire Academy Scientific Committee and Ethics approval was obtained from the IRB of the anti-doping laboratory in Qatar and conformed to the recommendations of the Declaration of Helsinki.

\subsection{Technical Information}

All physical and biochemical measures were carried out at three selected time points throughout the academic training season (September to May). Athlete screenings were performed at different time-points of the training cycle; a baseline measure (PRE - September); a mid-season (transition) measure (MID - February); an end of season measure (END - May).

\subsection{Anthropometric Characteristics}

Anthropometric and body composition characteristics were measured on the same day as the hematological measurements. Body mass using an electronic scale (Marsden, MGP250, UK), and height, sitting height and leg length using a stadiometer (Harpenden Stadiometer, Holtain, UK) were obtained on all subjects according to the standardised techniques adopted by the International Society for the Advancement of Kinanthropometry(ISAK). Peak height velocity (PHV) was determined using the equation proposed by Mirwald et al. (13). 


\subsection{Blood Collection and Analysis}

Athletes arrived in a fasted state (overnight) and reported to the laboratory $30 \mathrm{~min}$ before providing a blood sample. Venous blood was collected via venipuncture from an antecubital arm vein while at rest in a sitting position (we are aware of the need for venipuncture standardization requirements as it is our standard operating procedure) between 7:30 AM to 9:30 AM by a certified phlebotomist as per the regulatory requirements of Qatar law. The samples were collected in $3.0 \mathrm{~mL} \mathrm{K2}$ EDTA vacuum tubes and $4 \mathrm{~mL}$ serum separator tubes (SST 2 Advance) from Becton-Dickinson (BD, Franklin Lakes, USA).

All hematological markers were evaluated on the same day in a controlled laboratory setting $\left(20^{\circ} \mathrm{C}-22^{\circ} \mathrm{C}\right)$. Serum samples were allowed to coagulate at room temperature for $30 \mathrm{~min}$ and were then centrifuged at $1500 \mathrm{~g}$ for $15 \mathrm{~min}$ to separate the serum. After separation, samples were stored at $-80^{\circ} \mathrm{C}$ until further analysis.

The analysis for complete blood count was performed using a Sysmex XT2000i hematology analyzer (Sysmex, Kobe, Japan). The exercise-induced plasma volume (PV) changes were calculated according to Dill, and Costill (14). Serum samples were analysed on a Dimension XPand/RxL (Siemens, Erlangen, Germany) for a variety of biochemical parameters (total iron, ferritin, alanine- and aspartateaminotransferases, creatine kinase (CK), glucose, creatinine, cholesterol, high- and low- density lipoproteins, sodium, potassium, and chloride).

Furthermore, the concentration of testosterone, cortisol, sex hormone binding globulin (SHBG) were assessed using ELISA kits from R\&D (International Inc., New York, USA) while 25(OH)D was analysed with an ELISA kit from EAGLE (EAGLE BIOSCIENCE). The inter-assay coefficient of variation (CV) for testosterone ranged from $5.6 \%$ to $6.8 \%$, for cortisol from $9.3 \%$ to $21.2 \%$, for SHBG from $3.6 \%$ and $6.7 \%$ and for $25(\mathrm{OH}) \mathrm{D}$ from 7.0 to $8.6 \%$. The variation coefficient (intra-assay variability) was $<5 \%$ for all measurements. An erythrocyte sedimentation rate test (ESR) was also performed using automatic erythrocyte sedimentation analyzer (Sediplus S200, SARSDEDT).

\subsection{Physical Performance Testing}

All athletes performed four physical tests during three separate time points to determine their table tennis performance related characteristics. The physical tests chosen cover the main performance characteristics and competencies required to excel at table tennis during adolescence and are routinely used as part of normal assessments for children involved in sport (24; Ortega et al. 2010; Kondric et al. 2013). Physical performance testing sessions were completed within two days. All sessions were performed in the following order: a counter-movement jump
(CMJ), a sprint test (5, 10, 20 and $30 \mathrm{~m}$ ), a modified Aspire Table Tennis Agility Test (mATTAT) and a multi-stage fitness test (MSFT). Prior to testing, athletes underwent a guided routine warm-up by a strength and conditioning coach that lasted 10 min consisting of a 5 min general warmup and 5 min of running, jumping and stretching. The same protocol and intensity was repeated in all testing sessions. The physical performance testing procedures are described below in more detail.

\subsubsection{Day 1}

\subsubsection{Counter Movement Jump}

The CMJ (a vertical jump test) as previously used in youth athletes was performed to assess the explosive power of the leg musculature. The athletes were asked to perform the test with hands on hips and repeat this test a minimum of 3 times. A rest period of $30 \mathrm{~s}$ was provided in between each jump using the protocol already described by Komi and Bosco (15) on a KMS Jump mat (Fitness Technology, Adelaide, Australia). This test has previously been reported to be both valid and reliable (16). Jumping height was computed on a custom software (Ballistic Measurement System, Fitness Technology, Adelaide, Australia) measured as an estimate of the height change in the athlete's center of mass, taking into consideration the total duration the athlete spends in the air with no ground contact. The highest CMJ recorded was used for further analysis.

\subsubsection{Sprint Test}

Acceleration and maximum running speed were determined during the sprint test. The athlete was required to run a single maximal sprint over a $30 \mathrm{~m}$ distance. Sprint times were recorded using infrared timing gates (Fusion Sport Smartspeed, Queensland, Australia). The timing gates were positioned at $0 \mathrm{~m}, 5 \mathrm{~m}, 10 \mathrm{~m}, 20 \mathrm{~m}$ and $30 \mathrm{~m}$, with all the split times recorded. Previous research has established reliability with a CV of $\sim 2 \%$ for youth athletes performing all-out sprints over similar distances (17). The starting position was standardized for each sprint. All athletes repeated the test 3 times with a 3 min recovery period to ensure results were reliable. The times of the best $30 \mathrm{~m}$ sprint was then used for further analysis.

\subsubsection{Modified Aspire Table Tennis Agility Test}

The mATTAT (18) was used to measure table tennis specific agility and has previously been used in youth table tennis athletes. The protocol consisted of measuring the time taken to complete a set sequence of 5 table tennis specific motor tasks. The athlete starts with a table tennis racket in hand and is required to hit 3 stationary instrumented table tennis balls ( 2 of these are hit twice) in the 
correct sequence whilst ensuring good table tennis technique is used. The athlete performs 3 trials, $18 \mathrm{~s}$ apart with a $3 \mathrm{~s}$ countdown where the player must adopt a 'service return ready position'. The tester reviewed the output file to check whether the trial was valid. Any trial where the response time was below $0.55 \mathrm{~s}$ or where the table tennis ball was not hit was discarded and not deemed to be valid. Only the valid trials were analysed and the best (lowest) total time for the agility test and its associated stages was used for further analysis.

\subsubsection{Day 2}

\subsubsection{Multi-Stage Fitness Test}

The MSFT test is aimed at assessing maximal cardiorespiratory function and is a popular test for children involved in sport or physical activity. Athletes were asked to perform continuous running between two lines $20 \mathrm{~m}$ apart in relation to a recorded auditory signal. The athletes were required to run as long (as many levels) as they could, and the test was stopped if the athlete failed to reach the line (within $2 \mathrm{~m}$ ) for two consecutive times after receiving a warning. The athlete's score was the level and the number of shuttles $(20 \mathrm{~m})$ reached before he was unable to keep up with the auditory signal. This level score was then converted to a predicted $\mathrm{VO}_{2 \max }$ score $\left(\mathrm{p} \mathrm{VO}_{2 \max }\right.$ using a regression equation developed by Ramsbottom et al. (19).

\subsection{Typical Training Weekly Structure}

The maximal weekly training program of the athletes consisted of 8 training sessions per week which were characterized according to three basic types: 5-6 table tennis specific sessions, 1-2 strength \& conditioning sessions and 1 recovery session. This is in accordance with the operating procedure in our sports academy and in other academies around the world. All sessions had a maximum duration of $90 \mathrm{~min}$; accounting for a maximum total of $12 \mathrm{~h}$ per week. These are typical training times when comparing similar age groups in other sports. Training exposure data from absent and/or ill athletes were not accounted for. The exposure periods to training were during school periods, which took place from September until May. The average total training time per athlete over the examined training period was $237 \mathrm{~h} 42 \mathrm{~min}$.

\subsection{Statistics}

The normality of distribution of all hematological and biochemical parameters was examined in each group using the Shapiro-Wilk's test, confirming the homogeneity. The data were analyzed by means of the statistical package for social sciences (SPSS) for windows (SPSS, Chicago, IL, USA), IBM version 21. Differences between time-points were evaluated using a repeated measures ANOVA. To correct violations of sphericity, the degrees of freedom were corrected in a normal way, using Huynh-Feldt $(\varepsilon>0.75)$ or Greenhouse-Geisser $(\varepsilon<0.75)$ values for $\varepsilon$, as appropriate (20). The results are presented as the mean \pm standard deviation (SD) throughout the text, unless otherwise stated.

Effect sizes were determined by calculating Cohen's d. The magnitude of the effect size was classified as; trivial < 0.2, small 0.21-0.60, moderate 0.61-1.20, large 1.21-1.99, and very large $>2.0$ (21). The alpha level of significance was set at $5 \%(\mathrm{P}<0.05)$.

\section{Results}

Table 1 shows the group means ( \pm SD) for the anthropometric and performance related characteristics throughout a training year. Performance parameters tended to significantly improve over the training season. Athletes significantly improved sprint test times over 5,10 and $20 \mathrm{~m}$ at MID period (2.5 to 5.3\%) and END period (3.5 to 8.1\%) when compared to their PRE-scores $(\mathrm{P}<0.05)$. No significant changes were found over $30 \mathrm{~m}(\mathrm{P}>0.05)$.

Similarly, the $\mathrm{p} \mathrm{VO}_{2}$ values also showed significant improvements during the MID (3.4\%) and END (9.7\%) periods of the training season when compared to PRE-measures $(\mathrm{P}>0.05)$. The time of completion for the mATTAT $(11.2 \%)$ and the height of the CMJ (16.1\%) only showed significant improvements during the END period of the season when compared to PRE-measures $(\mathrm{P}<0.05)$.

Other measures of anthropometry or performance related characteristics showed no significant difference between any of the phases of training $(\mathrm{P}>0.05)$. There was no significant change in height, weight, BMI and PHV during the observed period $(\mathrm{P}>0.05)$.

Table 2 presents the effect of long- term training and competition on different hematological and iron status related markers in adolescent table tennis athletes. Hematric (Hct) percentages showed a main effect with lower values of $3.2 \%$ during PRE and 3.6\% during MID season, when compared to the END of season $(\mathrm{P}<0.05)$. RET concentrations were also lower by $22.9 \%$ during PRE and $10.9 \%$ during MID season when compared to end of season values $(\mathrm{P}<$ 0.017). Values for mean cell volume (MCV) displayed a similar trend with values 2.0\% lower during PRE and 2.7\% lower during MID season when compared to END of season values $(\mathrm{P}<0.001)$.

Conversely, values for mean corpuscular hemoglobin concentration (MCHC) during END of season decreased by $2.7 \%$ when compared to PRE-season and $2 \%$ when compared to MID-season values $\mathrm{P}<0.001)$. Further, the plasma volume for the whole group of athletes decreased by $3.6 \%$ in MID-period and by -5.9\% and END-period. 
Table 1. Anthropometric and Physiological Characteristics for the Entire Group of Adolescent Athletes (Mean \pm SD) at Baseline, MID Season and END Season TimePoints $^{\mathrm{a}}$

\begin{tabular}{|c|c|c|c|}
\hline Parameters & Baseline $\left(T_{1}\right)$ & $\operatorname{MID}$ Season $\left(T_{2}\right)$ & $\operatorname{END} \operatorname{Season}\left(T_{3}\right)$ \\
\hline Age, $y$ & $14.2 \pm 1.3$ & $14.6 \pm 1.3$ & $14.8 \pm 1.4$ \\
\hline Height, cm & $164.9 \pm 10.5$ & $166.5 \pm 10.3$ & $167.3 \pm 10.4$ \\
\hline Weight, Kg & $56.0 \pm 15.2$ & $57.6 \pm 15.3$ & $58.5 \pm 14.8$ \\
\hline BMI, $\mathrm{kg} / \mathrm{m}^{2}$ & $20.3 \pm 4.0$ & $20.5 \pm 4.0$ & $20.7 \pm 3.9$ \\
\hline PHV, y & $0.27 \pm 1.40$ & $0.61 \pm 1.40$ & $0.78 \pm 1.36$ \\
\hline $\mathrm{CMJ}, \mathrm{cm}$ & $29.07 \pm 5.63$ & $30.76 \pm 4.74$ & $33.74 \pm 8.16^{\mathrm{b}}$ \\
\hline $5 \mathrm{~m}$ sprint, $s$ & $1.22 \pm 0.07$ & $1.15 \pm 0.06^{\mathrm{b}}$ & $1.12 \pm 0.07^{\mathrm{b}, \mathrm{c}}$ \\
\hline 10m sprint, $s$ & $2.09 \pm 0.14$ & $2.03 \pm 0.12^{\mathrm{b}}$ & $2.0 \pm 0.13^{\mathrm{b}, \mathrm{c}}$ \\
\hline 20m sprint, s & $3.71 \pm 0.24$ & $3.61 \pm 0.22^{\mathrm{b}}$ & $3.58 \pm 0.20^{\mathrm{b}, \mathrm{c}}$ \\
\hline 30m sprint, $s$ & $5.27 \pm 0.37$ & $5.17 \pm 0.31$ & $5.14 \pm 0.31$ \\
\hline $\mathrm{pVO}_{2}, \mathrm{~mL} / \mathrm{kg} / \mathrm{min}$ & $45.65 \pm 6.45$ & $47.21 \pm 5.59$ & $50.07 \pm 7.68^{\mathrm{b}, \mathrm{c}}$ \\
\hline mATTAT, s & $3.27 \pm 0.35$ & $3.07 \pm 0.35$ & $2.91 \pm 0.32^{\mathrm{b}}$ \\
\hline
\end{tabular}

Abbreviations: BMI, body mass index; CMJ, countermovement jump; mATTAT, modified Aspire table tennis agility test; $\mathrm{PHV}$, peak height velocity (when negative is before $\mathrm{PHV}$, when positive, after $\mathrm{PHV}$ ); $\mathrm{P} \mathrm{VO}_{2}$, predicted $\mathrm{VO}_{2} ; \mathrm{T}$, time point ${ }^{\mathrm{a}} \mathrm{P}<0.05$.

${ }^{\mathrm{b}}$ Significantly different from phase $\mathrm{T}_{1}$.

${ }^{c}$ Significantly different from phase $\mathrm{T}_{2}$.

Table 3 presents the results of the various biochemical markers affected by long- term training and competition in adolescent table tennis athletes. A main effect was found for SHBG, which significantly decreased compared to ENDseason values $(\mathrm{P}<0.005)$. Serum testosterone showed a significant increase in the END-season period compared to PRE-season and MID-season values $(\mathrm{P}<0.01)$. 25(OH)D levels were also significantly higher during the END-season period when compared to PRE-season and MID-season values.

No significant variations were observed in any of the examined enzymes during these training periods. The effect size of the yearly changes of various biochemical parameters ranged from trivial to small with mean corpuscular hemoglobin content (MCHC), CK, glucose, testosterone and $25(\mathrm{OH}) \mathrm{D}$ indicating a moderate effect size (i.e. Cohen's $\mathrm{d}>0.60)$.

\section{Discussion}

Physical testing of athletes throughout the year helps build up an accurate physiological profile and helps coaches develop a tailored fitness program. In addition, it provides reference ranges to athletes and coaches to improve the quality of training prescription which helps facilitate the long-term athletic development. No information in the literature is available when it comes to provid- ing accurate training information on adolescent table tennis players which follow regular and structured training activities. Therefore, the first purpose of the study was to examine the yearly fluctuations of performance related parameters in adolescent table tennis athletes over a training season.

In general, it is well accepted that children's strength, anaerobic and aerobic power is trainable. Overall improvements may be smaller than those seen in adults. Young, physically active children, who are exposed to training activities can demonstrate significant gains of $13 \%-30 \%$ in muscle strength with resistance training as well as improvements of 5\% in aerobic fitness (for a review see (22)). Most studies are limited to specific training periods and it is unclear what the typical improvements are in young athletes involved in full-time table tennis programs. Previous work has highlighted the importance of tracking growth and development in young athletes in combination with physical performance $(23,24)$. The competitive demands of training and competition impose strains on certain physiological systems of young players. In turn, this produces adverse outcomes like injuries and/or burnout if not correctly managed (25). Therefore, routine screening activities and the daily monitoring of training can provide vital information, which is why previous studies highlight the need of assessing physical parameters.

Our results showed significant improvements during the END-period in measures of linear running speed over 5, 10 and $20 \mathrm{~m}, \mathrm{CMJ}$, mATTAT and predicted $\mathrm{VO}_{2 \max }$ across a training season when compared to PRE-measures. Only findings of linear running speed over 5, 10 and $20 \mathrm{~m}$, and $\mathrm{p} \mathrm{VO}_{2 \max }$ were significantly better MID-period compared to PRE-measures. Seasonal changes assessing longitudinal data for growth rates of various physical performance measures throughout adolescence in elite sport is limited (26). Previous research has generally been conducted in general populations $(27,28)$. In the present study, it was found that performance variables closely related to table tennis significantly improved at specific time-points of a training year. It is believed this could be due to athletes undergoing continuous training periods and/or growth (29, 30). Agility is a key component of fitness for table tennis players as players are required to move quickly in a variety of directions using numerous footwork techniques and speeds (18). We found that our players only significantly improved agility at the END-period of the season. Previous research in youth football players also found significant improvements in agility towards the END of the season or competition period (29). It could be suggested that a prolonged exposure to specific training activities is necessary before observing meaningful improvements in this quality as assessed by typical agility tests. The same pattern 


\begin{tabular}{|c|c|c|c|c|c|}
\hline Parameters & Baseline $\left(T_{1}\right)$ & MID Season $\left(T_{2}\right)$ & END Season $\left(T_{3}\right)$ & Cohen' d & Interpretation \\
\hline $\mathbf{R B C}, \mathbf{1 0}^{6} / \mu \mathbf{L}$ & $5.0 \pm 0.3$ & $5.1 \pm 0.2$ & $5.1 \pm 0.3$ & 0.33 & Small \\
\hline $\mathrm{Hb}, \mathrm{g} / \mathrm{dL}$ & $14.2 \pm 1.3$ & $14.2 \pm 1.2$ & $14.3 \pm 1.0$ & 0.08 & Trivial \\
\hline HCT, \% & $40.7 \pm 3.3$ & $40.5 \pm 2.8$ & $42.0 \pm 3.2^{\mathrm{b}, \mathrm{c}}$ & 0.39 & Small \\
\hline MCV, fl & $80.6 \pm 3.5$ & $80.1 \pm 3.5$ & $82.2 \pm 3.7^{\mathrm{b}, \mathrm{c}}$ & 0.44 & Small \\
\hline MCH, pg & $28.1 \pm 1.6$ & $28.0 \pm 1.6$ & $27.9 \pm 1.8$ & 0.11 & Trivial \\
\hline MCHC, $\mathbf{g} / \mathrm{DL}$ & $34.8 \pm 1.1$ & $35.0 \pm 1.1$ & $33.9 \pm 1.0^{b, c}$ & 0.85 & Moderate \\
\hline RET, \% & $0.84 \pm 0.28$ & $0.93 \pm 0.28$ & $1.03 \pm 0.36^{\mathrm{b}}$ & 0.53 & Small \\
\hline Ret-He, pg & $33.1 \pm 1.8$ & $32.5 \pm 2.5$ & $33.2 \pm 1.8$ & 0.05 & Trivial \\
\hline IRF, \% & $5.1 \pm 2.5$ & $5.6 \pm 2.6$ & $5.8 \pm 2.5$ & 0.28 & Small \\
\hline Iron, umol/L & $17.0 \pm 5.2$ & $14.0 \pm 4.7$ & $15.7 \pm 5.5$ & 0.24 & Small \\
\hline Fe, ug/L & $45.5 \pm 47.3$ & $42.9 \pm 35.4$ & $45.3 \pm 34.3$ & 0.01 & Trivial \\
\hline $\mathrm{WBC}, 10^{3} / \mu \mathrm{L}$ & $5.8 \pm 1.2$ & $5.8 \pm 1.4$ & $5.8 \pm 1.8$ & 0.01 & Trivial \\
\hline Neutrophils, \% & $43.7 \pm 9.2$ & $47.5 \pm 9.1$ & $47.0 \pm 11.4$ & 0.31 & Small \\
\hline Lymphocytes, \% & $42.7 \pm 8.2$ & $39.8 \pm 6.1$ & $40.6 \pm 11.1$ & 0.21 & Small \\
\hline Monocytes, \% & $8.8 \pm 2.4$ & $8.4 \pm 2.0$ & $8.1 \pm 1.3$ & 0.36 & Small \\
\hline Eosinophils, \% & $4.2 \pm 2.4$ & $3.8 \pm 2.4$ & $3.9 \pm 2.9$ & 0.11 & Trivial \\
\hline Basophils, \% & $0.48 \pm 0.20$ & $0.44 \pm 0.28$ & $0.41 \pm 0.13$ & 0.43 & Small \\
\hline Platelets, $\mathbf{1 0}^{\mathbf{3}} / \mu \mathbf{L}$ & $233.9 \pm 52.4$ & $256.2 \pm 57.7$ & $260.5 \pm 62.9$ & 0.47 & Small \\
\hline MPV, fl & $10.6 \pm 0.8$ & $10.4 \pm 0.9$ & $10.3 \pm 0.6$ & 0.42 & Small \\
\hline ESR, $\mathbf{m m} / \mathbf{h}$ & $2.8 \pm 1.8$ & $3.3 \pm 1.4$ & $3.7 \pm 2.7$ & 0.39 & Small \\
\hline$\% \Delta \mathbf{P V}$ & - & $-3.6 \%$ (PRE-MID) & $-5.9 \%$ (PRE-END) & - & \\
\hline
\end{tabular}

Abbreviations: \% $\triangle \mathrm{PV}$, plasma volume changes; ESR, erythrocyte sedimentation rate; Fe, ferritin; Hct, hematocrit; MCH, mean corpuscular hemoglobin; MCHC, mean corpuscular hemoglobin concentration; MCV, mean corpuscular volume; MPV, mean platelet volume; RBC, red blood cell; Hb, hemoglobin; Ret\%, reticulocyte percentage; Ret-He, reticulocyte hemoglobin equivalent; $\mathrm{T}$, time point; WBC, white blood cells.

${ }^{\mathrm{a}} \mathrm{P}<0.05$.

${ }^{\mathrm{b}}$ Significantly different from phase T1.

${ }^{\mathrm{c}}$ Significantly different from phase T2.

was observed in other measures of physical fitness as the bulk of training activities in this cohort was table tennis specific which further provides support as to why improvements in the mATTAT were only present at the END of season testing. Furthermore, agility is closely related to running speed (31) and has previously been observed to significantly improve in young athletes $(25,29)$ over varying distances ranging from 5 to $50 \mathrm{~m}$. Surprisingly, and in agreement with Dragijsky et al. (29), we also found that $30 \mathrm{~m}$ running speed did not show any changes over the course of the season. This is because table tennis training does not stimulate, or target skills related to $30 \mathrm{~m}$ linear running speed. The focus of training is targeted towards improving speed, agility and quickness (SAQ) while emphasizing specific table tennis game aspects, such as movement games and quick changes of direction and speed in a small space. A30m sprint test may be useful for establishing speed abilities in a generic population but can be considered redun- dant in a young table tennis cohort.

A well-developed aerobic energy system in table tennis is vital to help players cope with the demands of training and competition $(3,5)$. Seasonal changes in predicted $\mathrm{p} \mathrm{VO}_{2}$ has previously been assessed in young elite football athletes (29). It was found that seasonal changes in $\mathrm{p} \mathrm{VO}_{2 \max }$ are present following a specific training period, such as pre-season. However, when training does not focus specifically on improving or maintaining aerobic endurance, varying responses can be observed (32). Therefore, the observed improvements in endurance capacity observed at the END-period in our cohort of table tennis players is likely to be the effect of accumulated training load and strength and conditioning activities conducted throughout the training season. Improving explosive strength was a target during weekly strength and conditioning sessions (1-2 depending on training focus). Hence, the results of this study showed significant im- 


\begin{tabular}{|c|c|c|c|c|c|}
\hline Parameters & Baseline $T_{1}$ & $\operatorname{MID}$ Season $\left(T_{2}\right)$ & END Season $\left(T_{3}\right)$ & Cohen' d & Interpretation \\
\hline CK, U/L & $224.3 \pm 108.7$ & $274.9 \pm 193.3$ & $166.7 \pm 67.7$ & 0.63 & Moderate \\
\hline Creat., umol/L & $64.9 \pm 12.0$ & $65.3 \pm 18.8$ & $70.0 \pm 18.9$ & 0.32 & Small \\
\hline ALT, U/L & $28.9 \pm 11.5$ & $27.0 \pm 8.4$ & $26.0 \pm 8.2$ & 0.29 & Small \\
\hline AST, U/L & $24.6 \pm 15.7$ & $24.2 \pm 6.7$ & $22.4 \pm 7.0$ & 0.18 & Trivial \\
\hline Glu., nmol/L & $5.0 \pm 0.6$ & $5.6 \pm 0.9$ & $5.7 \pm 0.9^{b}$ & 0.91 & Moderate \\
\hline Chol., nmol/L & $3.8 \pm 0.6$ & $3.8 \pm 0.5$ & $3.7 \pm 0.5$ & 0.18 & Trivial \\
\hline HDL, nmol/L & $1.36 \pm 0.2$ & $1.40 \pm 0.3$ & $1.37 \pm 0.3$ & 0.03 & Trivial \\
\hline LDL, nmol/L & $2.24 \pm 0.5$ & $2.33 \pm 0.5$ & $2.16 \pm 0.4$ & 0.17 & Trivial \\
\hline $\mathrm{C}, \mathbf{n m o l} / \mathbf{L}$ & $227.5 \pm 74.9$ & $289.8 \pm 89.6$ & $261.8 \pm 104.5$ & 0.37 & Small \\
\hline $\mathrm{T}, \mathbf{n m o l} / \mathrm{L}$ & $21.2 \pm 10.0$ & $21.3 \pm 8.2$ & $28.5 \pm 5.4^{b, c}$ & 0.90 & Moderate \\
\hline $\mathrm{T} / \mathrm{C}$ ratio & $0.87 \pm 0.33$ & $0.65 \pm 0.31$ & $0.85 \pm 0.46$ & 0.04 & Trivial \\
\hline 25(OH)D, ng/mL & $32.2 \pm 1.5$ & $28.6 \pm 11.5^{\mathrm{b}}$ & $41.9 \pm 16.5^{\mathrm{b}, \mathrm{c}}$ & 0.82 & Moderate \\
\hline SHBG, nmol/L & $90.1 \pm 84.1$ & $112.4 \pm 80.4$ & $66.0 \pm 48.0^{c}$ & 0.34 & Small \\
\hline $\mathrm{Na}, \mathrm{nmol} / \mathrm{L}$ & $138.7 \pm 1.6$ & $137.6 \pm 1.3$ & $138.3 \pm 1.9$ & 0.27 & Small \\
\hline $\mathrm{K}, \mathbf{n m o l} / \mathbf{L}$ & $4.4 \pm 0.3$ & $4.3 \pm 0.3$ & $4.4 \pm 0.2$ & 0.01 & Trivial \\
\hline Cl., nmol/L & $101.4 \pm 1.4$ & $101.3 \pm 1.4$ & $101.1 \pm 2.2$ & 0.01 & Trivial \\
\hline
\end{tabular}

provements in CMJ at the END-period of the season. Our results yielded similar findings to a study performed by Bergeron et al. (25), which found CMJ to be improved significantly over a $3 y$ period in young football players. However, even though our results are like previous findings in elite adolescent athletes, these were conducted on football players and not table tennis players who are likely to perform more running and jumping activities. Therefore, it makes comparison between groups very difficult. Our study is the first to provide information on changes in physical variables in young table tennis players.

The secondary aim of the study was to report the variability of selected biomarkers utilized to ascertain health and training status and training effects. A few hematological parameters: $\mathrm{Hct}, \mathrm{MCV}$ and RET changed significantly over the course of this specific training period of 9 months. Because growth and maturation cannot be separated from training activities, it is difficult to quantify whether findings are due to training load and intensity or due to growth and maturation. Previous studies have found that red blood cells are relatively stable in adolescent athletes while levels of hemoglobin $(\mathrm{Hb})$ and Hct are found to be lower $(33,34)$. However, our results only found Hct levels to be increased during END-season (3.2\%) while concentration lev- els of $\mathrm{Hb}$ and red blood cells did not change. The observed variances between cohorts could be explained by the differing observation periods (longer) and the nature of the investigated sports in other studies. Most studies in the literature were conducted on youth athletes in other sports $(33,34)$.

Further, the mean value for total iron was close to the lower end of the clinical reference range $(14.0 \pm 4.7$ umol/L), which suggests that almost half of the athletes had a low concentration of iron (pediatric reference intervals). In addition, the mean value for ferritin $(42.9 \pm 35.4$ $\mathrm{ug} / \mathrm{L}$ ) suggests that the majority of athletes were on the borderline of the proposed clinical reference ranges for the adolescent population. Concerning MCV, a parameter related to microcytic anemia, has been reported to be deficient in the Middle East(35) and therefore essential to be assessed in young athletes from this region. Our cohort presented relatively low values when compared to similar age groups previously studied in the literature (33). Previous data on MCV in adolescent soccer athletes has shown a significant reduction after five months of a structured training period with no marked decrease in the red blood cell count (33). However, our results are like what has previously been observed in a bigger group of young Arab ath- 
letes (36). MCVvalues of $80.6 \pm 3.5$ (fl) at baseline screening increased progressively to $82.3 \pm 1.7$ (fl) at the END period of the training season.

The process of erythropoiesis can be monitored through the measurement of RET-He, RET\% and IRF in growing athletes. RET are the earliest form of erythrocytes released into the blood and have been identified to be an important indicator of effective erythropoiesis (37). In this study, the mean values for adolescent table tennis players ranged from $0.84 \pm 0.28 \%$ at PRE-screening and increased to $1.03 \pm 0.36 \%$ in May (END of season), displaying a high rate of erythropoiesis which is in line with other studies.

It has been established that elevated cortisol levels at rest can reflect long-term training stress $(38,39)$ while the testosterone to cortisal ratio has been proposed to indicate the balance between anabolic and catabolic activity. Many researchers suggest that a decrease of $30 \%$ or more implies overtraining and/or an unfavored level of anabolic to catabolic hormonal balance $(8,40)$. Cortisol concentrations did not significantly change throughout the season, although mean cortisol values during mid-season peaked. However, testosterone levels were significantly higher during the END period of the training season. It is believed to be because of in-season supplementation of 25(OH)D (41). Further, testosterone levels increased in parallel to a decrease in SHBG. Testosterone is largely bound to SHBG and albumin. Therefore, as SHBG falls the level of bioavailable testosterone increases over the same period. Although the testosterone/cortisol ratio decreased by $25 \%$ during MID period, this variation was not significant. Moreover, results showed that 25(OH)D significantly decreased during MID period, resulting in athletes receiving 25(OH)D supplementation through recommendation from the medical team. As a result, 25(OH)D displayed a significant increase at the END-period.

The training process and growth rates in adolescent athletes in table tennis causes several changes in various physical, hematological and biochemical markers related to health and performance. The relevance of such observations on a specific population in order to enhance training prescription and health interventions is of great importance. Finally, as the aim of this study was to report some initial observations on a table tennis cohort, we hope that the data provided in this pilot work can be the beginning of a series of studies aimed at improving our understanding of training and adaptations in young table tennis players in order to provide effective and appropriate training guidelines to safeguard athletes' health. This study can provide more information on how regular monitoring and evaluation of biochemical and hematological markers can help (a) prevent the adverse effects of intense exercise, (b) assist in the design of training programs that will safe- guard athletes' health, and (c) improve table tennis performance.

This study is not without limitations. The lack of control group means we are unable to compare our results simultaneously with recreational athletes. Furthermore, we had a sample size small as our aim was to examine high level athletes, which are members of the national table tennis team and students of Aspire Academy, which restricted the amount of individuals that could be utilized for this study.

\subsection{Conclusions}

In conclusion, based on our findings, changes occur in certain physical parameters, biochemical and hematological markers, throughout the training period. Therefore, coaches, sports scientists and nutritionists should take into consideration these fluctuations to plan and alter their training programs and provide specific nutritional strategies if required.

\section{Acknowledgments}

We would like to acknowledge the Aspire Academy table tennis athletes for their contribution as participants. We would also like to acknowledge Andrew Douglas, Anthony Hazeldine, Mohammed Hamdy, Mohamed El Sayed and Saleh Al Marri for their help during anthropometric and body composition measurements. We also would like to thank Aspetar Orthopaedic and Sports Medicine Hospital for the analysis of some biochemical parameters.

\section{Footnotes}

Authors' Contribution: Study concept and design: Samuel Andrew Pullinger, Evdokia Varamenti and Marco Cardinale; analysis and interpretation of data: Samuel Andrew Pullinger and Evdokia Varamenti; drafting of the manuscript: Samuel Andrew Pullinger and Evdokia Varamenti; critical revision of the manuscript for important intellectual content: Samuel Andrew Pullinger, Evdokia Varamenti, Marco Cardinale, Zoran Nikolovski and Mohamed Elgingo; statistical analysis: Samuel Andrew Pullinger, Evdokia Varamenti.

Conflict of Interests: It is not declared by the authors.

Ethical Approval: The study was approved by the Aspire Academy Scientific Committee and Ethics approval was obtained from the IRB of the anti-doping laboratory in Qatar. This study is part of a larger study on growth and maturation of young athletes.

Financial Disclosure: No financial interests related to the material in the manuscript. 


\section{Funding/Support: No funding or support received.}

\section{References}

1. Girard O, Millet GP. Neuromuscular fatigue in racquet sports. Phys Med Rehabil Clin N Am. 2009;20(1):161-73. ix. doi: 10.1016/j.pmr.2008.10.008. [PubMed:19084769].

2. Kondrič M, Milić R, Furjan-Mandić G. Physiological anaerobic characteristic of Slovenian elite table tennis players. Acta Univ Palacki Olomuc Gymn. 2007;37(3):68.

3. Kondric M, Zagatto AM, Sekulic D. The physiological demands of table tennis: A review. J Sports Sci Med. 2013;12(3):362-70. [PubMed: 24149139]. [PubMed Central: PMC3772576].

4. Lees A. Technique analysis in sports: A critical review. $J$ Sports Sci. 2002;20(10):813-28. doi: 10.1080/026404102320675657. [PubMed: 12363297].

5. Jones AM, Winter EM, Davison RCR, Bromley PD, Mercer TH. Sport and exercise physiology testing guidelines: The british association of sport and exercise sciences guide. 2007.

6. Hawley JA. Adaptations of skeletal muscle to prolonged, intense endurance training. Clin Exp Pharmacol Physiol. 2002;29(3):218-22. doi: 10.1046/j.1440-1681.2002.03623.x. [PubMed: 11906487].

7. Petibois C, Cazorla G, Poortmans JR, Deleris G. Biochemical aspects of overtraining in endurance sports: A review. Sports Med. 2002;32(13):867-78. doi: 10.2165/00007256-200232130-00005. [PubMed: 12392446].

8. Adlercreutz H, Harkonen M, Kuoppasalmi K, Naveri H, Huhtaniemi I, Tikkanen $\mathrm{H}$, et al. Effect of training on plasma anabolic and catabolic steroid hormones and their response during physical exercise. Int $J$ Sports Med. 1986;7 Suppl 1:27-8. doi: 10.1055/s-2008-1025798. [PubMed: 3744643].

9. Arabi A, El Rassi R, El-Hajj Fuleihan G. Hypovitaminosis D in developing countries-prevalence, risk factors and outcomes. Nat Rev Endocrinol. 2010;6(10):550-61. doi: 10.1038/nrendo.2010.146. [PubMed: 20852586].

10. Bischoff HA, Borchers M, Gudat F, Duermueller U, Theiler R, Stahelin $\mathrm{HB}$, et al. In situ detection of 1,25-dihydroxyvitamin D3 receptor in human skeletal muscle tissue. Histochem J. 2001;33(1):19-24. doi: 10.1023/A:1017535728844. [PubMed: 11352397].

11. Muhairi SJ, Mehairi AE, Khouri AA, Naqbi MM, Maskari FA, Al Kaabi J, et al. Vitamin D deficiency among healthy adolescents in Al Ain, United Arab Emirates. BMC Public Health. 2013;13:33. doi: 10.1186/1471-2458-1333. [PubMed: 23311702]. [PubMed Central: PMC3610121].

12. Koehler K, Braun H, Achtzehn S, Hildebrand U, Predel HG, Mester J, et al. Iron status in elite young athletes: Gender-dependent influences of diet and exercise. Eur J Appl Physiol. 2012;112(2):513-23. doi: 10.1007/s00421-011-2002-4. [PubMed: 21594695].

13. Mirwald RL, Baxter-Jones AD, Bailey DA, Beunen GP. An assessment of maturity from anthropometric measurements. Med Sci Sports Exerc. 2002;34(4):689-94. doi: 10.1249/00005768-200204000-00020. [PubMed: 11932580].

14. Dill DB, Costill DL. Calculation of percentage changes in volumes of blood, plasma, and red cells in dehydration. J Appl Physiol. 1974;37(2):247-8. doi:10.1152/jappl.1974.37.2.247. [PubMed: 4850854].

15. Komi PV, Bosco C. Utilization of stored elastic energy in leg extensor muscles by men and women. Med Sci Sports. 1978;10(4):261-5. [PubMed: 750844]

16. Markovic G, Dizdar D, Jukic I, Cardinale M. Reliability and factorial validity of squat and countermovement jump tests. J Strength Cond Res. 2004;18(3):551-5. doi: 10.1519/15334287(2004)18<551:RAFVOS>2.0.CO;2. [PubMed: 15320660].

17. Oliver JL, Armstrong N, Williams CA. Reliability and validity of a soccer-specific test of prolonged repeated-sprint ability. Int J Sports Physiol Perform. 2007;2(2):137-49. doi: 10.1123/ijspp.2.2.137. [PubMed: 19124901].
18. Glynn J, Rusga T, Hartley J, Mulloy F, Moore J, Williams B, et al. Implications for physical preparation of cadet male table tennis players: Analysis of the 2013 championship singles final. International Conference of Biomechanics in Sports. 2014.

19. Ramsbottom R, Brewer J, Williams C. A progressive shuttle run test to estimate maximal oxygen uptake. Br J Sports Med. 1988;22(4):1414. doi: 10.1136/bjsm.22.4.141. [PubMed: 3228681]. [PubMed Central: PMC1478728].

20. Field A. Discovering statistics using SPSS. 2nd ed. London: Sage Publications, Inc; 2005.

21. Cohen J. Statistical power analysis for the social sciences. New York: Routledge Academic; 1988.

22. Matos N, Winsley RJ. Trainability of young athletes and overtraining. J Sports Sci Med. 2007;6(3):353-67. [PubMed: 24149422]. [PubMed Central: PMC3787286].

23. Armstrong N, Barker AR. Endurance training and elite young athletes. Med Sport Sci. 2011;56:59-83. doi: 10.1159/000320633. [PubMed: 21178367].

24. Winsley R, Matos N. Overtraining and elite young athletes. Med Sport Sci. 2011;56:97-105. doi:10.1159/000320636. [PubMed: 21178369].

25. Bergeron MF, Mountjoy M, Armstrong N, Chia M, Cote J, Emery CA, et al. International Olympic Committee consensus statement on youth athletic development. Br J Sports Med. 2015;49(13):843-51. doi: 10.1136/bjsports-2015-094962. [PubMed: 26084524].

26. Williams CA, Oliver JL, Faulkner J. Seasonal monitoring of sprint and jump performance in a soccer youth academy. Int J Sports Physiol Perform. 2011;6(2):264-75. doi: 10.1123/ijspp.6.2.264. [PubMed: 21725111]

27. Beunen G, Malina RM. Growth and physical performance relative to the timing of the adolescent spurt. Exerc Sport Sci Rev.1988;16:503-40. doi: 10.1249/00003677-198800160-00018. [PubMed: 3292266].

28. Viru A, Loko J, Harro M, Volver A, Laaneots L, Viru M. Critical periods in the development of performance capacity during childhood and adolescence. Eur J Phys Ed.1999;4(1):75-119.

29. Dragijsky M, Maly T, Zahalka F, Kunzmann E, Hank M. Seasonal variation of agility, speed and endurance performance in young elite soccer players. Sports (Basel). 2017;5(1). doi: 10.3390/sports5010012. [PubMed: 29910372]. [PubMed Central: PMC5969008]

30. Wilmore JH, Costill DL, Kenney WL. Physiology of sport and exercise. 4 th ed. Champaign: Uman Kinetics; 1994.

31. Castagna C, Chaouachi A, Rampinini E, Chamari K, Impellizzeri F. Aerobic and explosive power performance of elite italian regionallevel basketball players. J Strength Cond Res. 2009;23(7):1982-7. doi: 10.1519/JSC.0b013e3181b7f941. [PubMed:19855321].

32. Bangsbo J, Findley L. Exercise and training physiology: A simple approach. Sweden: SISU Sports Books; 2011.

33. Andelkovic M, Baralic I, Dordevic B, Stevuljevic JK, Radivojevic N, Dikic N, et al. Hematological and biochemical parameters in elite soccer players during a competitive half season. J Med Biochem. 2015;34(4):460-6. doi: 10.2478/jomb-2014-0057. [PubMed: 28356856]. [PubMed Central: PMC4922354].

34. Manna I, Khanna G, Dhara P. Effect of training on morphological, physiological and biochemical variables of U-19 soccer players. Baltic J Health Phys Activity. 2011;3(4):237.

35. Hwalla N, Al Dhaheri AS, Radwan H, Alfawaz HA, Fouda MA, Al-Daghri $\mathrm{NM}$, et al. The prevalence of micronutrient deficiencies and inadequacies in the middle east and approaches to interventions. Nutrients. 2017;9(3). doi: 10.3390/nu9030229. [PubMed: 28273802]. [PubMed Central: PMC5372892].

36. Voss SC, Varamenti E, Elzain Elgingo M, Bourdon PC. New parameters and reference values for monitoring iron status in Middle Eastern adolescent male athletes. J Sports Med Phys Fitness. 2014;54(2):179-85. [PubMed: 24509989].

37. Banfi G, Del Fabbro M. Behaviour of reticulocyte counts and immature reticulocyte fraction during a competitive season in elite ath- 
letes of four different sports. Int J Lab Hematol. 2007;29(2):127-31. doi: 10.1111/j.1751-553X.2006.00847.x. [PubMed: 17474885].

38. Brunelli DT, Rodrigues A, Lopes WA, Gaspari AF, Bonganha V, Montagner PC, et al. Monitoring of immunological parameters in adolescent basketball athletes during and after a sports season. J Sports Sci. 2014;32(11):1050-9. doi: 10.1080/02640414.2013.878806. [PubMed: 24479737].

39. Papadopoulos E, Muir C, Russell C, Timmons BW, Falk B, Klentrou P. Markers of biological stress and mucosal immunity during a week leading to competition in adolescent swimmers. J Immunol
Res. 2014;2014:234565. doi: 10.1155/2014/234565. [PubMed: 25025080] [PubMed Central: PMC4082920].

40. Jurimae J, Jurimae T, Purge P. Plasma testosterone and cortisol responses to prolonged sculling in male competitive rowers. J Sports Sci. 2001;19(11):893-8. doi: 10.1080/026404101753113840. [PubMed: 11695511].

41. Heijboer AC, Oosterwerff M, Schroten NF, Eekhoff EM, Chel VG, de Boer RA, et al. Vitamin D supplementation and testosterone concentrations in male human subjects. Clin Endocrinol (Oxf). 2015;83(1):105-10 doi: 10.1111/cen.12711. [PubMed: 25557316]. 